\title{
Nanocomposite plasters for the treatment of superficial tumors by chemo-photothermal combination therapy
}

This article was published in the following Dove Press journal: International Journal of Nanomedicine

\section{Wei Qi \\ Jing Yan \\ Haifeng Sun \\ Hua Wang}

Institute of Medicine and Materials Applied Technologies, College of Chemistry and Chemical Engineering, Qufu Normal University, Qufu, Shandong 273165, China
Correspondence: Wei Qi; Hua Wang Institute of Medicine and Materials Applied Technologies, College of Chemistry and Chemical Engineering, Qufu Normal University, Qufu, Shandong 273165, China Tel +860537445 630I: +8605374456306 Email qiwei@mail.qfnu.edu.cn; huawangqfnu@I26.com
Introduction: Novel nanomedical systems are being developed as multiple therapeutic modalities because the combinational therapies for cancer on a single platform can have larger chance to address tumor heterogeneity and drug resistance than any mono-therapeutic modality.

Methods: In this study, photothermal therapy (PTT) and chemotherapy (CT) were combined to treat squamous cell carcinoma by using a novel type of noninvasive plaster composed of carboxylated-reduced graphene oxide ( $\mathrm{rGO}-\mathrm{COOH}$ ), gold nanorods ( $\mathrm{Au} \mathrm{NRs}$ ), and doxorubicin (DOX). Firstly, DOX was loaded onto rGO-COOH to form DOX_rGO-COOH. Then, the obtained DOX_rGO-COOH and Au NRs were co-assembled to obtain nanocomposite multilayer. rGO-COOH and Au NRs were combined together to obtain high light-to-heat conversion efficiency. Using them as photothermal agents for PTT and using DOX in $\mathrm{rGO}-\mathrm{COOH}$ as an anticancer drug for $\mathrm{CT}$, their synergistic combination therapy could be applicable practically. Results: As a result, DOX_rGO-COOH/Au NRs showed higher photothermal effects than that showed by $\mathrm{rGO}-\mathrm{COOH}$ or $\mathrm{Au}$ NRs alone. It also showed higher therapeutic effects than DOX_rGO-COOH (for CT) or Au nr (for PTT) alone. Moreover, the system can repeatedly produce heat and simultaneously stimulate the release of the encapsulated anticancer drug into the tumor upon being irradiated by near-infrared laser. In vivo experiments demonstrated that the squamous cell carcinoma-bearing mice treated with DOX_rGO-COOH/Au NRs were healthy for more than 60 days without tumor recurrence.

Conclusion: The as-developed DOX_rGO-COOH/Au NRs plaster could be an effective, convenient, and noninvasive treatment option for treating superficial tumors.

Keywords: nanocomposite plaster, carboxylated-reduced graphene oxide, doxorubicin, $\mathrm{Au}$ nanorods, superficial tumor

\section{Introduction}

Cancer is one of the most common life-threating diseases and a leading cause of deaths worldwide. Although chemotherapy (CT) remains the major therapeutic approach for treatment of most of the cancers, photothermal therapy (PTT) has efficiently treated superficial tumors in preclinical studies. For example, it is currently being tested in clinical trials for treating superficial head and neck cancer by Nanospectra Biosciences, Inc. ${ }^{1}$ PTT, also known as PT ablation or optical hyperthermia, has been actively explored as a promising alternative or supplement to conventional cancer treatment approaches due to its remote controllability, minimal invasion, easy applicability, and low systemic toxicity. ${ }^{1,2}$ It employs PT agents to generate sufficient heat to raise the local temperature under specific light exposure. ${ }^{3,4}$ The heat can cause irreversible 
cellular damage leading to cell death. Moreover, numerous reports have found that mild PT heating can enhance the cellular uptake of chemotherapeutic drugs. ${ }^{5,6}$ Thus, the combination of PTT and CT has been proposed to yield a synergistic effect with better antitumor efficiency and more clinical applications. ${ }^{7-10}$ Some composite systems have been prepared including mesoporous silica nanoparticles, ${ }^{11,12}$ graphene quantum dots, ${ }^{13}$ metal-organic framework ${ }^{14}$ for combinational PTT and CT cancer treatment. Li et al reported a carrier-free theranostic system co-assembled with chemotherapeutic drug, epirubicin (EPI), and photothermal agent, indocyanine green (ICG) for dual-modal imaging-guided synergistic chemo-PTT. ${ }^{15}$

For this combinational treatment, the development of PT agents, which can absorb and convert light to heat efficiently, would be a key point. ${ }^{16}$ Various PT transducers, including organic compounds, ${ }^{17-19}$ metal nanostructures, ${ }^{20-23}$ copper chalcogenide semiconductors, ${ }^{24-26}$ and carbon-based materials, ${ }^{27-30}$ have been reported for the therapy of tumors. Among the carbon-based materials, graphene oxide (GO), particularly reduced $\mathrm{GO}$ ( $\mathrm{rGO}$ ), has become the most competitive PT agents due to its optical transparency, high chemical stability, and effective light-to-heat conversion. ${ }^{31,32}$ However, the low quantum efficiency of rGO and its broad absorption spectrum render it less sensitive to specific wavelengths. ${ }^{33,34}$ To overcome these limitations and to enhance the PT effect, rGO-Au composite systems have been proposed. . $^{35,36}$

Gold ( $\mathrm{Au})$ nanostructures including aggregates of colloidal particles, nanoshells, nanocages, nanorods, and nanocrosses have received increasing attention in the field of PTT in recent years due to the fact that their localized surface plasmon resonance (SPR) confers them with the capability to absorb light at a specific wavelength and efficiently convert the photon energy into heat. ${ }^{37}$ Importantly, the SPR peaks can be easily tuned by altering their size, shape, structure, or a combination of these parameters, for example, unlike spherical nanoparticles, which absorb light in the visible region, Au nanorods (Au NRs) shift the excitation wavelength to the near-infrared (NIR) region. The use of NIR light is preferred for PTT because water, melanin, and hemoglobin have absorption minima between 700 and $900 \mathrm{~nm}$, and the light at this wavelength is most likely to pass directly through the tissues without significant heat generation. ${ }^{38}$

Despite their potential therapeutic effects, treatments with PTT nanomaterials that are delivered to tumors either intravenously or intratumorally, are often repeated because of incomplete tumor cell ablation and tumor recurrence resulting from localized hyperthermia and rapid clearance of the nanomaterials from the tumor sites. Multiple and frequent injections of these nanomaterials may cause adverse side effects and patient discomfort.

Here, we developed a type of nanocomposite plaster with Layer-by-Layer (LbL) assembly technique aiming to use it as a novel strategy for superficial cancer treatment. It can repeatedly produce heat, and simultaneously, release the encapsulated anticancer drug into the tumor upon NIR laser. The LbL method for fabrication of thin films has become a subject of intensive research for various biomedical applications, from drug delivery, ${ }^{39,40}$ cellular adhesive surfaces ${ }^{41,42}$ to tissue regeneration. ${ }^{43,44}$ Until now, various kinds of materials, such as nanoparticles, ${ }^{45}$ dendrimers,${ }^{46}$ charged small molecules, ${ }^{47}$ DNA origami, ${ }^{48}$ carbon nanotubes,${ }^{49}$ fullerenes, ${ }^{50}$ and graphene, ${ }^{51}$ have been incorporated in the LbL films along with polyelectrolytes due to versatility and simplicity of the method. For example, we have constructed functional thin composite films by incorporating rGO or GO into the $\mathrm{LbL}$ multilayer for potential biomedical applications, such as biosensing ${ }^{52,53}$ and biointerface construction. ${ }^{54,55}$

In this study, doxorubicin (DOX) has been used as a chemotherapeutic agent and adsorbed onto carboxylated-reduced graphene oxide ( $\mathrm{rGO}-\mathrm{COOH}$ ) forming DOX_rGO-COOH. Then, the formed DOX_rGO-COOH was co-assembled with $\mathrm{Au}$ NRs to fabricate the DOX_rGO-COOH/Au NRs multilayer. We studied the synergistic PTT and CT effects of the multilayer in vitro and in vivo, as shown in Scheme 1. Its toxicity has been evaluated before and after NIR light radiation in human skin squamous cancer cells, A-431. The therapeutic efficacy of the film has been investigated in vivo using squamous cell carcinoma-bearing mice. Particularly, we have revealed that the combination of DOX_rGO-COOH and $\mathrm{Au}$ NRs in the composite multilayer considerably enhances the therapeutic effects, thus allowing it to act as a superior therapeutic plaster against skin cancer.

\section{Materials and methods Chemicals and materials}

Polyethyleneimine solution (PEI, 50\% in $\mathrm{H}_{2} \mathrm{O}$ ), DOX hydrochloride, and gold (III) chloride trihydrate $\left(\mathrm{HAuCl}_{4} \cdot 3 \mathrm{H}_{2} \mathrm{O}\right)$ were purchased from Sigma-Aldrich (St Louis, MO, USA). Expandable graphite 8099200 was purchased from Qingdao BCSM. Co. Ltd. (Laixi, China). Cetyltrimethylammonium bromide (CTAB), $\mathrm{NaBH}_{4}, \mathrm{AgNO}_{3}, \mathrm{HCl}$, and $\mathrm{NaOH}$ were gained from Tianjin Damao Chemical Reagent Co. Ltd. (Tianjin, China). 98\% $\mathrm{H}_{2} \mathrm{SO}_{4}, 30 \% \mathrm{H}_{2} \mathrm{O}_{2}$, and $\mathrm{KMnO}_{4}$ were purchased from Shanghai Chenyun Chemical and Engineering Company (Shanghai, China). All the chemical 

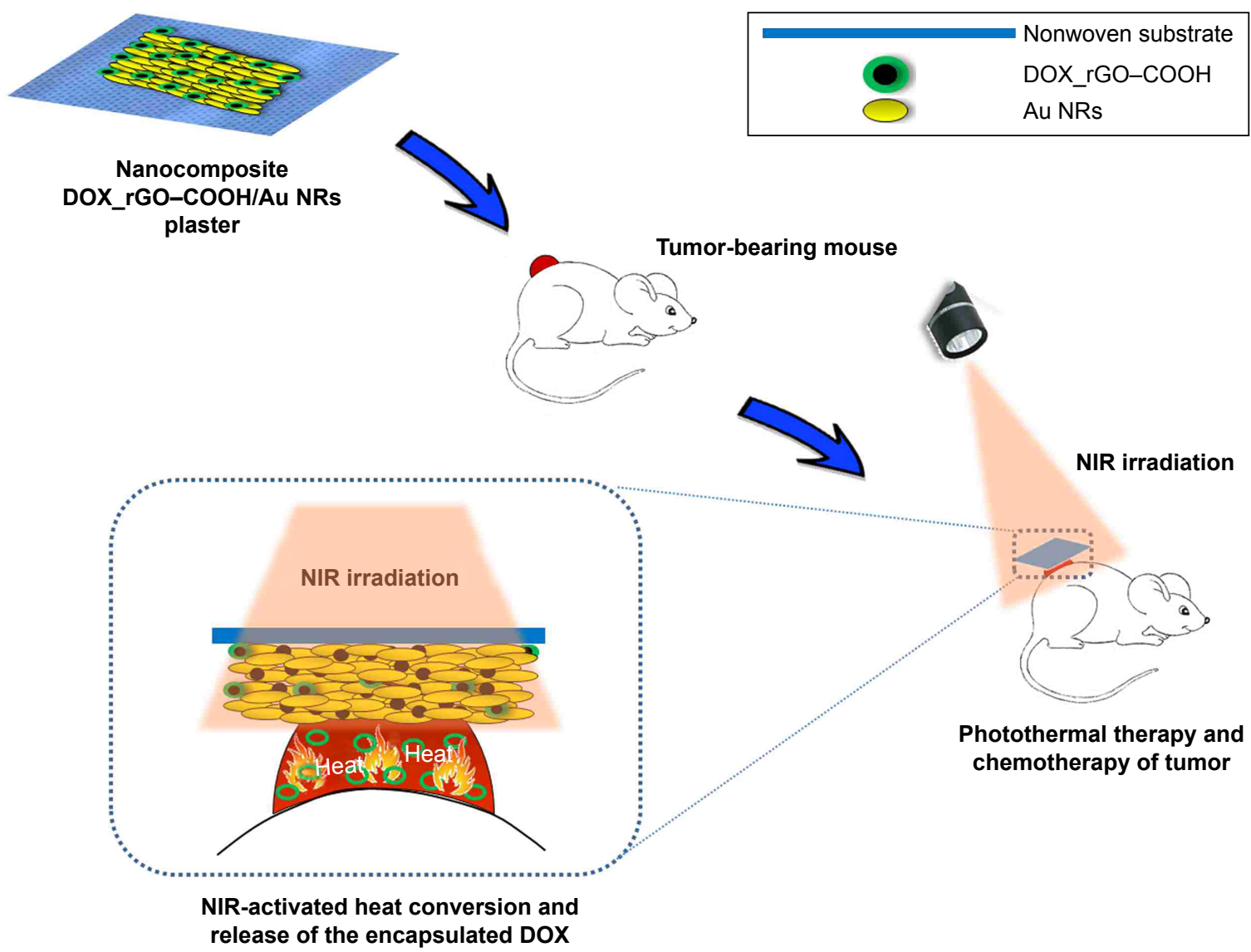

Scheme I Schematic representation of the fabricated plaster composed of DOX_rGO-COOH and Au NRs and it's in vivo application. Abbreviations: Au NRs, gold nanorods; DOX, doxorubicin; $\mathrm{rGO}-\mathrm{COOH}$, carboxylated-reduced graphene oxide; NIR, near infrared.

reagents were used as received without further purification. A diode laser ( $808 \mathrm{~nm}$ ) was bought from Beijing Optoelectronic Technology Co. Ltd. (Beijing, China). The water used in this work has been purified using Millipore Milli-Q system (Burlington, MA, USA).

\section{Synthesis of Au NR}

$\mathrm{Au}$ NR were synthesized by traditional seed-mediated method. ${ }^{56}$ Firstly, gold seeds were prepared by adding

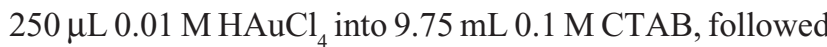
by gentle mixing. Subsequently, $600 \mu \mathrm{L} 0.01 \mathrm{M}$ ice-cold $\mathrm{NaBH}_{4}$ was added immediately. The above system was incubated for 2 hours at $28^{\circ} \mathrm{C}-30^{\circ} \mathrm{C}$ and left undisturbed until further use. Then, nanorod growth solution was prepared by mixing $2 \mathrm{~mL} 0.01 \mathrm{M} \mathrm{HAuCl}_{4}, 400 \mu \mathrm{L} 0.01 \mathrm{M} \mathrm{AgNO}_{3}, 800 \mu \mathrm{L}$ $0.1 \mathrm{M} \mathrm{HCl}$, and $40 \mathrm{~mL} \mathrm{0.1} \mathrm{M} \mathrm{CTAB}$. Finally, $200 \mu \mathrm{L}$ gold seed solution was added when the growth solution became colorless, and the system was stored at $30^{\circ} \mathrm{C}$ overnight. The Au NRs were collected and purified by centrifugation (10,000 rpm, 10 minutes), and the pellet was resuspended into Millipore water.

\section{Preparation of $\mathrm{rGO}-\mathrm{COOH}$}

GO was synthesized by modified Hummers' method using graphitic powders. ${ }^{57}$ Firstly, 0.5 g graphitic powder and $25 \mathrm{~mL}$ concentrated $\mathrm{H}_{2} \mathrm{SO}_{4}$ were mixed under ice bath and stirred for 2 hours. Then, $2.5 \mathrm{~g} \mathrm{KMnO}_{4}$ was added, heated to $35^{\circ} \mathrm{C}$ for 4 hours. Next, with the addition of $50 \mathrm{~mL}$ water, the reaction was maintained for 40 minutes at $98^{\circ} \mathrm{C}$. Further, $150 \mathrm{~mL}$ water was added into the system to dilute it, and $30 \%$ $\mathrm{H}_{2} \mathrm{O}_{2}$ was added to stop the reaction. Finally, the mixture was filtered through $0.45 \mu \mathrm{m}$ filter membrane and washed repeatedly until the $\mathrm{pH}$ of the filtrate was within the range of 5-6. The filter was redispersed into water and stored until further use. Next, GO-COOH was obtained as described previously. ${ }^{58}$ Briefly, $\mathrm{NaOH}(1.4 \mathrm{~g})$ and $\mathrm{Cl}-\mathrm{CH}_{2}-\mathrm{COOH}$ $(1 \mathrm{~g})$ were added to $\mathrm{GO}(2 \mathrm{mg} / \mathrm{mL}, 10 \mathrm{~mL})$ suspension and sonicated for 2 hours at $80^{\circ} \mathrm{C}$. The reaction can convert $-\mathrm{OH}$ on $\mathrm{GO}$ to $-\mathrm{COOH}$ via conjugation of acetic acid moieties and can partially reduce GO into $\mathrm{GGO}$. The resulting $\mathrm{rGO}-\mathrm{COOH}$ solution was quenched with $\mathrm{HCl}(20 \%)$, washed until neutral $\mathrm{pH}$ was obtained, and purified by repeated centrifugation (4,000 rpm, 20 minutes). 


\section{Loading of DOX onto rGO-COOH}

DOX was loaded on to $\mathrm{rGO}-\mathrm{COOH}$ by mixing DOX solution $(2 \mathrm{mg} / \mathrm{mL})$ with $\mathrm{rGO}-\mathrm{COOH}$ dispersion $(1 \mathrm{mg} / \mathrm{mL})$. The absorption time was 12 hours under dark conditions. DOX_ rGO-COOH was collected by centrifugation at $8,000 \mathrm{rpm}$ for 10 minutes. After being washed twice by water, drug loading was evaluated using ultraviolet-visible spectrophotometry (UV-Vis) absorbance at $488 \mathrm{~nm}$. The loading efficiency was calculated by the following equation:

$$
D O X_{\text {loaded }} \%=\frac{D O X_{\text {total }}-D O X_{\text {free }}}{D O X_{\text {total }}} \times 100 \%
$$

\section{Fabrication of DOX_rGO-COOH/Au NRs multilayer}

DOX_rGO-COOH/Au NRs multilayer was fabricated using the LbL assembly technique. In this study, some substrates, such as glass slides, quartz wafers, and clinical nonwoven fabric, were used for different characterization. To increase the hydrophilicity of the nonwoven fabric, it was treated with plasma cleaner for 5 minutes before assembly. Multilayers were constructed by alternate deposition of DOX_rGO-COOH and Au NRs onto the substrate. Each deposition was performed with the help of vacuum drying, and the deposition cycles were determined by the desired number of layers. While in the case of glass slides and quartz wafers, they were firstly treated with piranha solution $\left(98 \% \mathrm{H}_{2} \mathrm{SO}_{4}: 30 \% \mathrm{H}_{2} \mathrm{O}_{2}=7: 3\right.$ ) overnight to obtain the hydroxylated surface. Then, PEI $(1.5 \mathrm{mg} / \mathrm{mL}$, in $0.15 \mathrm{M}$ $\mathrm{NaCl}$ ) was adsorbed as the first layer for the successive assembly. Steps were repeated to obtain a desired number of layers. In this study, DOX_rGO-COOH/Au NRs with four bilayers, defined as (DOX_rGO-COOH/Au NRs) was used for in vitro and in vivo evaluation. It was calculated by mass evaluation that $0.39 \mu \mathrm{g} / \mathrm{mm}^{2}$ of $\mathrm{rGO}-\mathrm{COOH}$ and $0.44 \mu \mathrm{g} / \mathrm{mm}^{2}$ of Au NRs were deposited in each cycle averagely.

\section{Release of DOX from DOX_rGO- $\mathrm{COOH} / \mathrm{Au} \mathrm{NRs}$ multilayer}

DOX release experiments were performed in PBS with and without $808 \mathrm{~nm}$ laser radiation $\left(0.7 \mathrm{~W} \mathrm{~cm}^{-2}\right)$, respectively. In both the cases, DOX_rGO-COOH and DOX_rGO-COOH/ Au NRs were immersed in PBS. The supernatant was examined at different time points by measuring the absorbance at $488 \mathrm{~nm}$. This experiment was performed three times for each sample. The cumulative release of DOX was determined by the following equation:

$$
D O X_{\text {released }} \%=\frac{D O X_{\text {released }}}{D O X_{\text {initial }}} \times 100 \%
$$

\section{Characterization}

The size and distribution of Au NRs were evaluated by transmission electron microscope (TEM) JEM-1011 (JEOL, Tokyo, Japan). The zeta-potentials of $\mathrm{rGO}-\mathrm{COOH}$ and Au NRs were determined by Zetasizer Nano ZS ZEN 3600 (Malvern Instruments, Malvern, UK). In this study, all UV-Vis absorption spectra were obtained from UV3600 spectroscope (Shimadzu Corp., Kyoto, Japan), and Fourier transform infrared spectroscopy (FTIR) spectra were obtained from Tensor-27 (Bruker Corporation, Billerica, MA, USA). The surface morphology of DOX_rGO-COOH/Au NRs was observed using Nanoscope IIIa apparatus (Digital Instruments, Santa Barbara, CA, USA). Temperature change of all systems was monitored using DAE905k thermometer (SENDAE, Beijing, China).

\section{Cell culture}

Human skin squamous cancer cells A-431 were purchased from Center for Type Culture Collection of Wuhan University (Wuhan, China). A-431 cells were cultured in Eagle's minimum essential medium (EMEM) supplemented with $10 \%(\mathrm{v} / \mathrm{v})$ fetal bovine serum, $1.0 \mathrm{mM}$ pyruvate sodium, and 100 units $/ \mathrm{mL}$ penicillin/streptomycin at $37^{\circ} \mathrm{C}$ in a $\mathrm{CO}_{2}$ incubator (Thermo Fisher Scientific, Waltham, MA, USA) with $5 \% \mathrm{CO}_{2}$. Multiplication of cells in the logarithmic phase was conducted with $0.05 \%$ trypsin.

\section{Cell viability}

Cell viability was evaluated using a live/dead assay kit (Thermo Fisher Scientific). Seven experimental groups, namely tissue culture polystyrene (TCPS) as a control group, blank glass slide, $\mathrm{rGO}-\mathrm{COOH}$ on glass slide, Au NRs on glass slide, rGO-COOH/Au NRs on glass slide, DOX_rGO$\mathrm{COOH}$ on glass slide, DOX_rGO-COOH/Au NRs on glass slide, were investigated. Briefly, cells $\left(1.5 \times 10^{4}\right.$ cells $\left./ \mathrm{mL}\right)$ were seeded in each well of a 24-well cell culture plate. Each group was divided into two parts, one part was cultured normally (without NIR laser radiation) and the other under $808 \mathrm{~nm}$ laser radiation $\left(0.7 \mathrm{~W} \mathrm{~cm}^{-2}, 10\right.$ minutes). For those systems under radiation, cells were cultured for another 6 hours before adding live/dead assay solution containing 
calcein-AM and propidium iodide (PI). The fluorescence images were obtained with confocal laser scanning microscopy (CLSM) FV 1000 (Olympus Corporation, Tokyo, Japan). Quantitative analysis of cell viability was determined by CCK-8 assay for all the groups.

\section{Animal experiments}

Animal experiments were performed following the guidelines and animal ethical regulations published by the Ministry of Science and Technology of the People's Republic of China. The experiments in this study were approved by Animal Care and Use Committee of Institute of Process Engineering, Chinese Academy of Sciences, where the experiments were conducted. Four-week-old female BALB/c nude mice weighting 20-25 g supplied by State Key Laboratory of Biochemical Engineering (Beijing, China) were used as animal models for the evaluation of in vivo therapy effects. A-431 cells $\left(1.0 \times 10^{7}\right)$ in EMEM were injected into the right hind leg of mice. When the tumor volume grew to approximately $120 \mathrm{~mm}^{3}$, the mice were divided randomly into seven groups: the normal growth control group, the group using blank nonwoven substrate as a plaster onto the tumor, the $\mathrm{rGO}-\mathrm{COOH}$ treatment group, the $\mathrm{Au}$ NRs group, the $\mathrm{rGO}-\mathrm{COOH} / \mathrm{Au} \mathrm{NRs}$ group, the DOX_rGO$\mathrm{COOH}$ group, and the DOX_rGO-COOH/Au NRs group. Each group could be further divided into two parts, one part received no radiation and the other received NIR laser radiation $\left(0.7 \mathrm{~W} \cdot \mathrm{cm}^{-2}, 10\right.$ minutes $)$. After laser treatment, tumor volume and mouse body weight for all the groups were measured every 2 days until 16 days. The tumor size was determined using a caliper and was calculated with the formula: tumor volume $=\left(\right.$ length $\times$ width $\left.^{2} / 2\right) .{ }^{59}$

\section{Histological assessment of the tumor tissue}

For the histological analysis, two mice from each group were sacrificed after 16 days of laser treatment. The tumor tissues were resected, fixed in $4 \%$ paraformaldehyde solution, embedded in paraffin, sliced to $5 \mu \mathrm{m}$ thickness, and stained by H\&E, and observed under AxioImager A1 optical microscope (Carl Zeiss AG, Oberkochen, Germany).

\section{Statistical analysis}

There are three mice in each experimental group for comparison. The comparison results between groups were all calculated through Student's $t$-test using an analysis of variance. Difference was considered to be significant when
$* * P<0.01, * P<0.05$. All data were expressed as mean or mean $\pm \mathrm{SD}$.

\section{Results and discussion Preparation and characterization of DOX_rGO-COOH/Au NRs multilayer}

Firstly, the formed rGO-COOH was characterized by FTIR. As shown in Figure 1A, in the spectrum of GO, the broad and intense band at $3,406 \mathrm{~cm}^{-1}$ can be assigned to the $\mathrm{O}-\mathrm{H}$ stretching vibration. The peak at $1,730 \mathrm{~cm}^{-1}$ can be attributed to the stretching vibration of $\mathrm{C}=\mathrm{O}$ in carboxylic acid or carbonyl moieties, while the peak at $1,622 \mathrm{~cm}^{-1}$ corresponds to $\mathrm{C}=\mathrm{C}$ bonding of aromatic rings in the $\mathrm{GO}$ carbon skeleton structure. In the case of $\mathrm{rGO}-\mathrm{COOH}$, the $\mathrm{C}-\mathrm{O}$ stretching vibration at $1,050 \mathrm{~cm}^{-1}$ in the primary alcohol and the $\mathrm{O}-\mathrm{H}$ stretching vibration at $3,400 \mathrm{~cm}^{-1}$ significantly decrease. Meanwhile, the $\mathrm{C}-\mathrm{O}$ stretching vibration at $1,221 \mathrm{~cm}^{-1}$ in alkyl aryl ether disappear totally. These results confirmed the formation of $\mathrm{rGO}-\mathrm{COOH}$.

Then, DOX, a common anticancer drug, was adsorbed onto $\mathrm{rGO}-\mathrm{COOH}$ by mixing the nanosheets with DOX solution, this absorption was based on $\pi-\pi$ stacking and the electrostatic interaction between them. After the resulting DOX_rGO-COOH was collected by centrifugation, no free DOX could be detected in the supernatant by UV-Vis spectrometer, meaning that the loading percentage of DOX on $\mathrm{rGO}-\mathrm{COOH}$ can be calculated as $100 \%$ according to the equation (1). It could also be expressed as $0.21 \mathrm{mg} / \mathrm{mg}$ of DOX adsorbed by rGO-COOH. Simultaneously, from the UV-visible spectra (Figure 1B), the peak at $488 \mathrm{~nm}$ can be observed in both DOX and DOX_rGO-COOH, which corresponds to the characteristic absorption of DOX.

Another nanomaterial, Au NRs, was fabricated by the seed-mediated method using CTAB as a surfactant, and the fabrication of Au NRs was established by UV-visible spectroscopy (Figure 1B). The absorption spectrum of Au NRs shows two peaks at $510 \mathrm{~nm}$ (radial surface plasma resonance) and $853 \mathrm{~nm}$ (longitudinal surface plasma resonance [LSPR]). From the TEM images (Figure 1C), the prepared Au NRs are observed to be well-dispersed and stable with $72.2 \mathrm{~nm}$ length and $16.6 \mathrm{~nm}$ width. While in Figure 1D, the lattice parameter of $0.235 \mathrm{~nm}$ in the high resolution TEM (HR-TEM) of Au NRs could correspond to Au 111 lattice. Meanwhile, the zeta potentials of $\mathrm{Au}$ NRs and $\mathrm{rGO}-\mathrm{COOH}$ (Figure S1) were determined to be $42.4 \pm 4.1 \mathrm{mV}$ and $-51.4 \pm 4.5 \mathrm{mV}$, respectively, which facilitates the following assembly. 

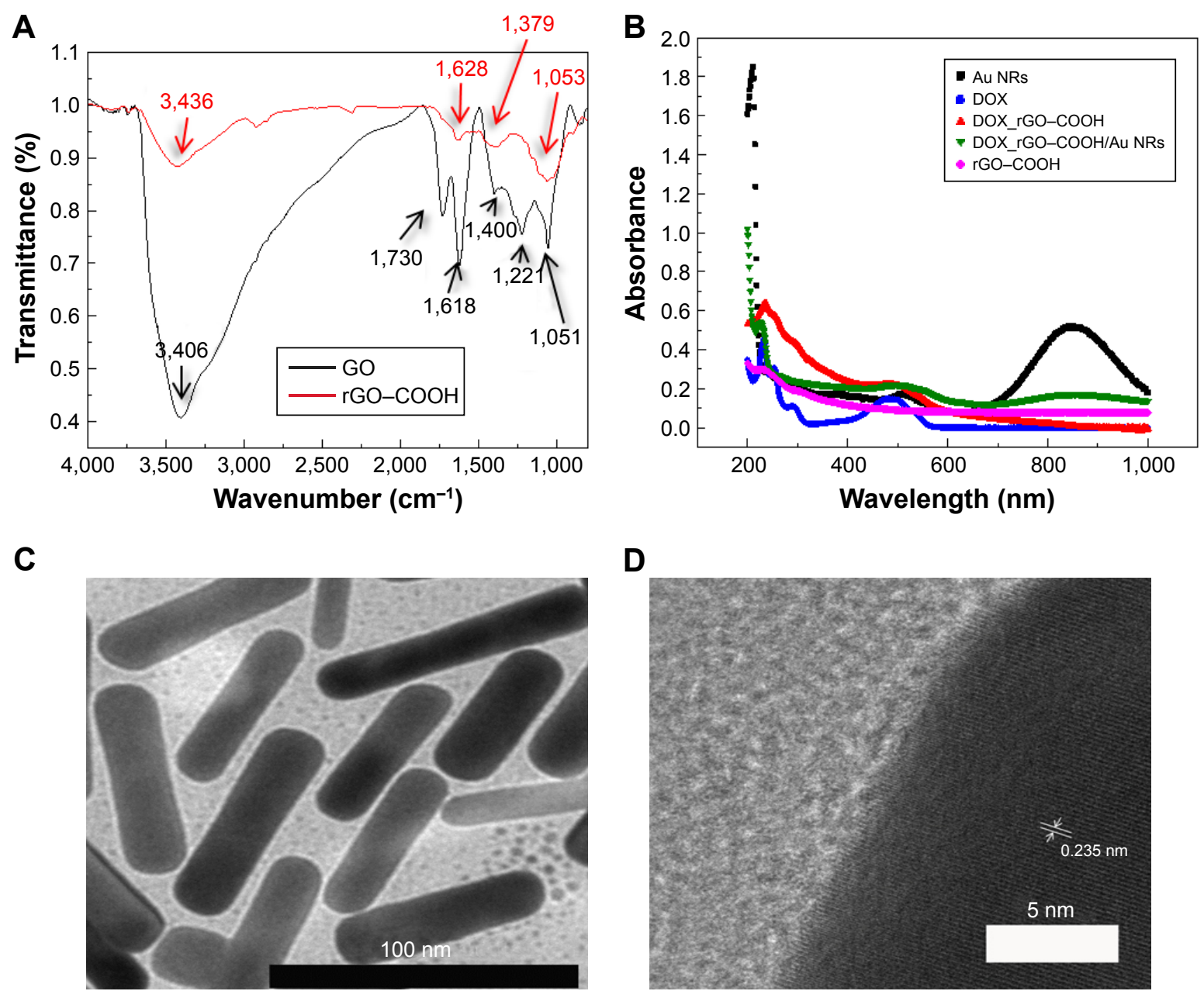

$\mathbf{D}$

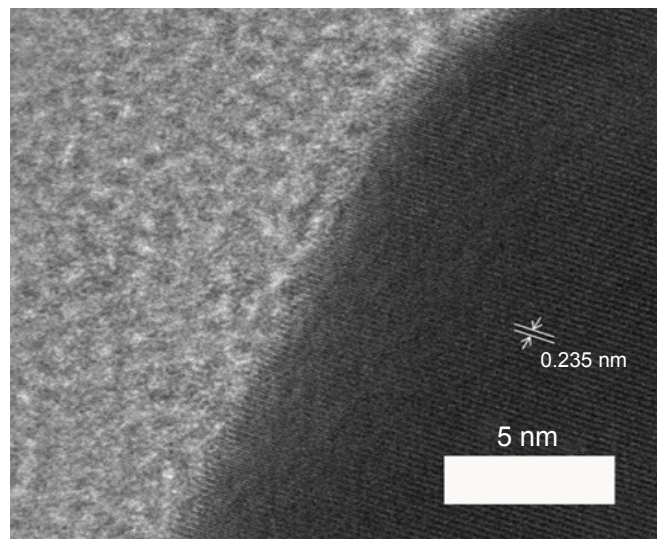

Figure I (A) FTIR spectra of GO and rGO-COOH; (B) UV-Vis spectra of Au NRs, DOX, DOX_rGO-COOH, DOX_rGO-COOH/Au NRs, and rGO-COOH; (C) TEM image of Au NRs. The scale bar is $100 \mathrm{~nm}$; (D) high-resolution TEM image of Au NRs.

Abbreviations: Au NRs, gold nanorods; DOX, doxorubicin; FTIR, Fourier transform infrared spectroscopy; GO, graphene oxide; rGO-COOH, carboxylated-reduced GO; TEM, transmission electron microscope; UV-Vis, ultraviolet-visible spectrophotometry.

The as-developed DOX_rGO-COOH and Au NRs were assembled alternately via the LbL technique. From the UV-visible spectra (Figure 1B), characteristic absorptions of DOX at $488 \mathrm{~nm}$ and the LSPR peak of Au NRs at $858 \mathrm{~nm}$ are observed. Additionally, surface morphology of the multilayer is shown in Figure S2, and the presence of rGO nanosheets and Au NRs can be easily observed from the image. Meanwhile, the exterior appearance of the plaster was photographed and compared with blank nonwoven fabric (Figure S3). It is obvious that nonwoven textile could be used as a substrate to load DOX_rGO-COOH and Au NRs.

\section{DOX release behavior of DOX_rGO- $\mathrm{COOH} / \mathrm{Au}$ NRs multilayer}

The drug release behavior of the multilayer was studied in PBS at $37^{\circ} \mathrm{C}$, especially the effect of NIR radiation on the multilayer, as receiving or not receiving laser radiation ( $808 \mathrm{~nm}, 0.7 \mathrm{~W} \mathrm{~cm}^{-2}, 10$ minutes). According to the equation (2), the cumulative release of DOX is profiled against time as shown in Figure 2, indicating that DOX is significantly released from the DOX_rGO-COOH/Au NRs multilayer when laser radiation is applied, while the release becomes obviously slow at laser-off state. The same experiment was performed on DOX_rGO-COOH and a similar release tendency is noted, except for a lower cumulative release of DOX. Thus, the NIR radiation apparently promoted the release of DOX at different time points, which may be attributed to the increase of mobility in DOX and the weakening of interaction between DOX and $\mathrm{rGO}-\mathrm{COOH}$ resulting from the heat converted from NIR radiation. Moreover, the DOX release can be repeatedly activated by NIR light and modulated by the number of laser On/Off cycles. Therefore, the PT effect 

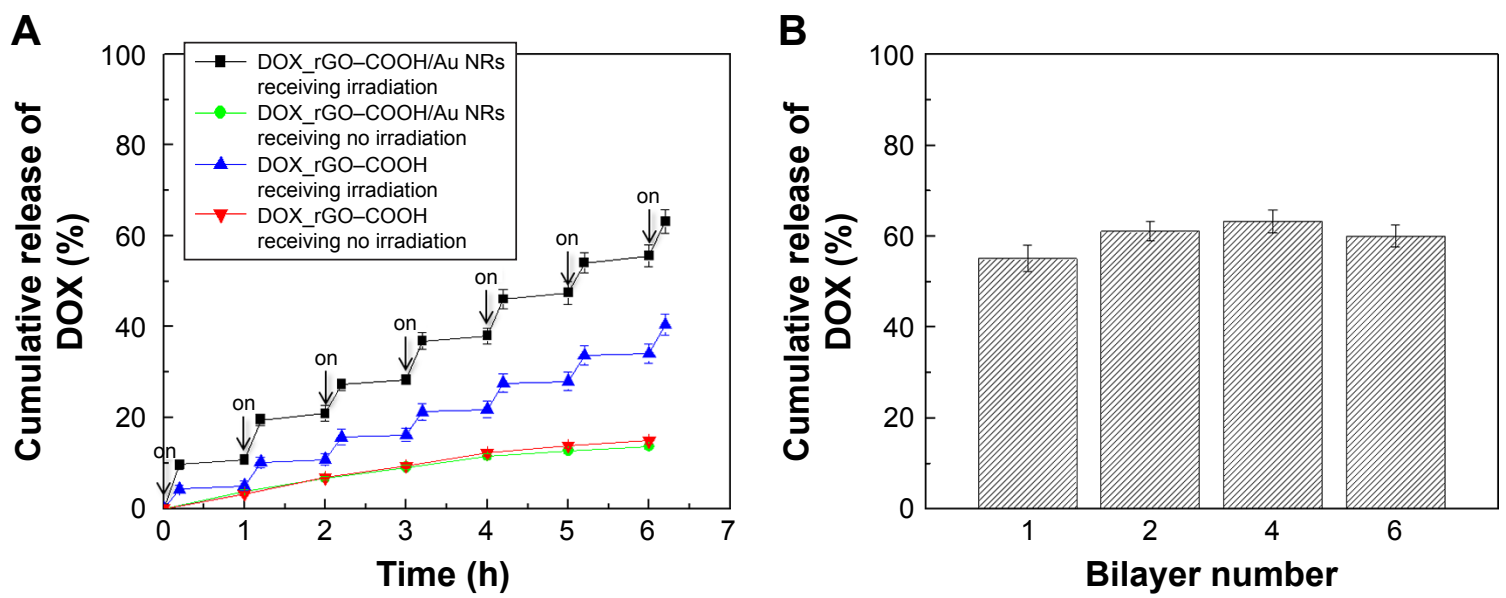

Figure 2 (A) The release profile over time of DOX_rGO-COOH and (DOX_rGO-COOH/Au NRs) in PBS with NIR radiation and without NIR radiation (808 nm, $0.7 \mathrm{~W} \mathrm{~cm}^{-2}$ ), respectively. Each radiation lasted 10 minutes. (B) The cumulative release of DOX is profiled over DOX_rGO-COOH/Au NRs layer number after seven discontinued laser radiations.

Abbreviations: Au NRs, gold nanorods; DOX, doxorubicin; NIR, near infrared; rGO-COOH, carboxylated-reduced graphene oxide.

of the DOX_rGO-COOH/Au NRs multilayer repeatedly facilitated precise and controlled release of anticancer drugs, by which a large cumulative release of DOX (63.2\%) was finally obtained. As a comparison, the cumulative release of DOX from the DOX_rGO-COOH/Au NRs multilayer with different layer number was investigated in the same way. As shown in Figure 2B, there is no significant difference among the studied systems, but the value for (DOX_rGO-COOH/Au $\mathrm{NRs})_{6}$ is slightly lower than that of (DOX_rGO-COOH/Au $\mathrm{NRs})_{4}$, meaning that the promoted release of DOX from the multilayer by laser illumination might be blocked somewhat by more layers than four bilayers.

\section{PT effects of rGO-COOH/Au NRs multilayer}

Depending on the strong NIR absorption of the rGO-COOH/ Au NRs multilayer, a significant PT effect can be expectedly observed during NIR radiation. To investigate this effect, NIR laser (808 $\mathrm{nm}, 0.7 \mathrm{~W} \cdot \mathrm{cm}^{-2}, 10$ minutes) was applied to $\mathrm{rGO}-\mathrm{COOH}$ dispersion in water $(20 \mu \mathrm{g} / \mathrm{mL}), \mathrm{Au}$ NRs dispersion in water $(22 \mu \mathrm{g} / \mathrm{mL})$, and ( $\mathrm{rGO}-\mathrm{COOH} / \mathrm{Au} \mathrm{NRs})_{4}$ multilayer with a diameter of $2 \mathrm{~mm}$ in water, respectively. Here, $\mathrm{rGO}-\mathrm{COOH}$ or Au NRs was used in the same amount as that in the $\mathrm{rGO}-\mathrm{COOH} / \mathrm{Au}$ NRs multilayer. The change in temperature was recorded every 120 seconds. The ultrapure water was used as a control. Temperature trends of the four systems with the radiation time are shown in Figure 3A. For the Au NRs system, the temperature rises rapidly from $25^{\circ} \mathrm{C}$ to $49.8^{\circ} \mathrm{C}$ within 10 minutes. A rise in temperature from $25^{\circ} \mathrm{C}$ to $42.6^{\circ} \mathrm{C}$ is observed for rGO-COOH system, while the temperature of the pure water increases only about $2^{\circ} \mathrm{C}$ under similar conditions. However, during the radiation process, rGO-COOH/Au NRs significantly improve the PT heating effect as a temperature of $60.0^{\circ} \mathrm{C}$ is achieved, which may be attributed to the coupling of the PT effects of rGO and $\mathrm{Au} \mathrm{NRs.}{ }^{60}$ Furthermore, the $\mathrm{rGO}-\mathrm{COOH} / \mathrm{Au}$ NRs multilayer shows a photothermal conversion efficacy which is dependent on layer number (Figure 3B). The temperature rises with increasing layer number but from ( $\mathrm{rGO}-\mathrm{COOH} / \mathrm{Au}$ $\mathrm{NRs})_{4}$ to (rGO-COOH/Au NRs) 6 the increase in temperature is not so significant as that from ( $\mathrm{rGO}-\mathrm{COOH} / \mathrm{Au} \mathrm{NRs})_{1}$ to (rGO-COOH/Au NRs) ${ }_{2}$ and from (rGO-COOH/Au NRs) to (rGO-COOH/Au NRs) ${ }_{4}$. Similar as the above discussion of the DOX release, the photothermal conversion might be blocked by upper layers. Overall, these results suggest that the as-assembled $\mathrm{rGO}-\mathrm{COOH} / \mathrm{Au} \mathrm{NRs}$ could be a rather effective PT converter of $808 \mathrm{~nm}$ laser radiation.

\section{Cytotoxicity of (DOX_rGO-COOH/Au $\mathrm{NRs})_{4}$ multilayer}

Owing to the excellent PT effects of the film, its therapeutic effect on cancer cells was evaluated. Seven experimental groups including TCPS control, blank nonwoven substrate, $\mathrm{rGO}-\mathrm{COOH}, \mathrm{Au} \mathrm{NRs}, \mathrm{rGO}-\mathrm{COOH} / \mathrm{Au}$ NRs, DOX_rGO-COOH, and DOX_rGO-COOH/Au NRs were maintained. Firstly, the cytotoxicity of all the groups in A-431 cells was investigated by CCK-8 assay (Figure 4A). After the cells are incubated with each group for 24 hours, there is no obvious cytotoxicity for TCPS, blank nonwoven fabrics, rGO-COOH, Au NRs, and $\mathrm{rGO}-\mathrm{COOH} / \mathrm{Au}$ NRs, where the cell viabilities are all higher than $90 \%$, except for those of DOX_rGO-COOH and DOX_rGO-COOH/Au NRs, the cell 

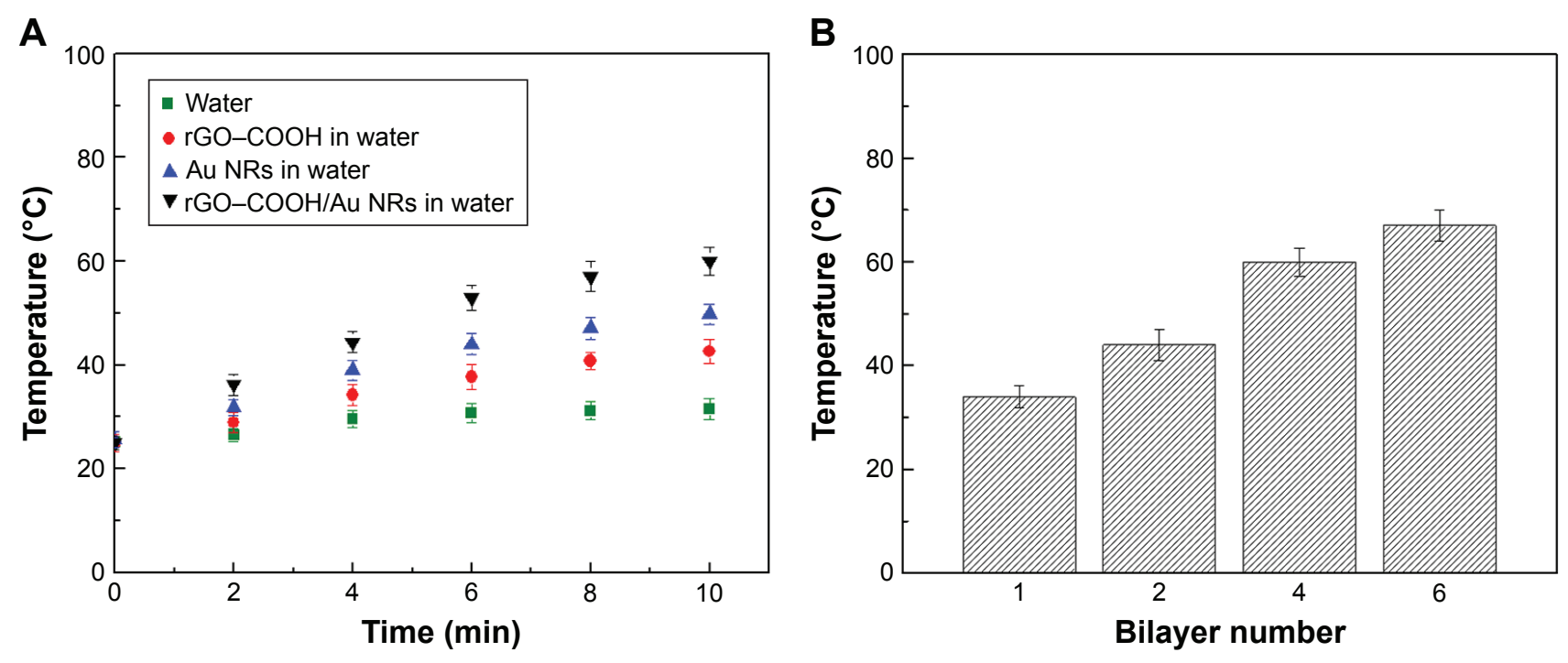

Figure 3 (A) Change in temperature of $\mathrm{rGO}-\mathrm{COOH}, \mathrm{Au} \mathrm{NRs}$, and $(\mathrm{rGO}-\mathrm{COOH} / \mathrm{Au} \mathrm{NRs})_{4}$ in water after NIR radiation $\left(808 \mathrm{~nm}, 0.7 \mathrm{~W} \mathrm{~cm}^{-2}\right)$. Pure water was irradiated similarly as a control. (B) The temperature changes of the $\mathrm{rGO}-\mathrm{COOH} / \mathrm{Au}$ NRs multilayer are profiled over layer number after 10 minutes radiation. Abbreviations: Au NRs, gold nanorods; NIR, near infrared; rGO-COOH, carboxylated-reduced graphene oxide.

viabilities are much lower, $63 \%$ and $59 \%$, respectively. This might be due to the released DOX from the film. Then, to further determine the PT therapeutic efficacy, the cells cultured for 12 hours in all the groups were exposed to $808 \mathrm{~nm}$ light at the power intensity of $0.7 \mathrm{~W} \mathrm{~cm}^{-2}$ for 10 minutes followed by the cell viability assessment again. The results show that
DOX_rGO-COOH/Au NRs multilayer can effectively kill the cells under NIR radiation showing the lowest cell viability of $17 \%$, which suggests that the combinatorial therapy has a much higher efficacy than that of individual treatments. Additionally, the cells cultured for another 6 hours after laser irradiation were co-stained by Calcine $\mathrm{AM}(\mathrm{Ca} \mathrm{AM})$ and PI
A

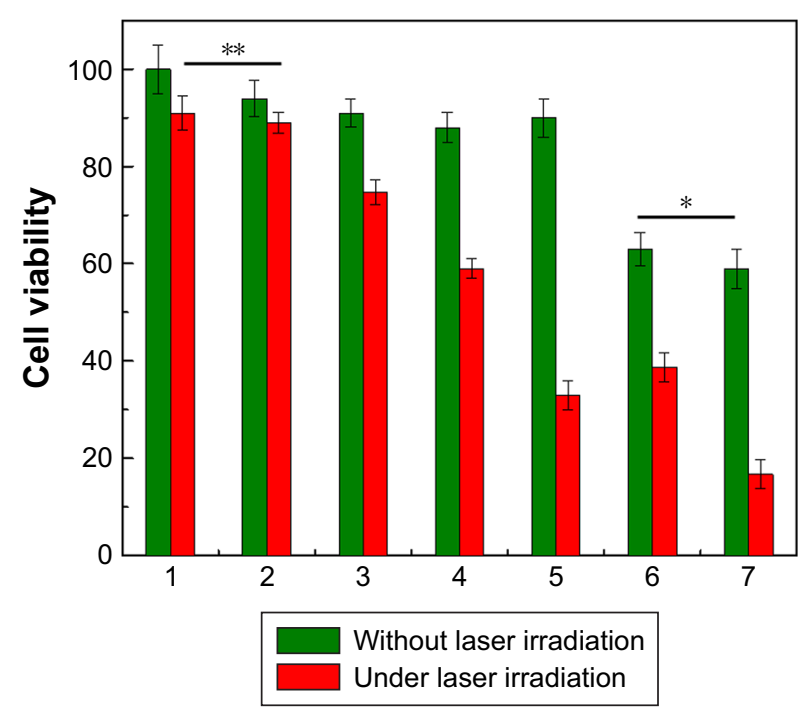

B
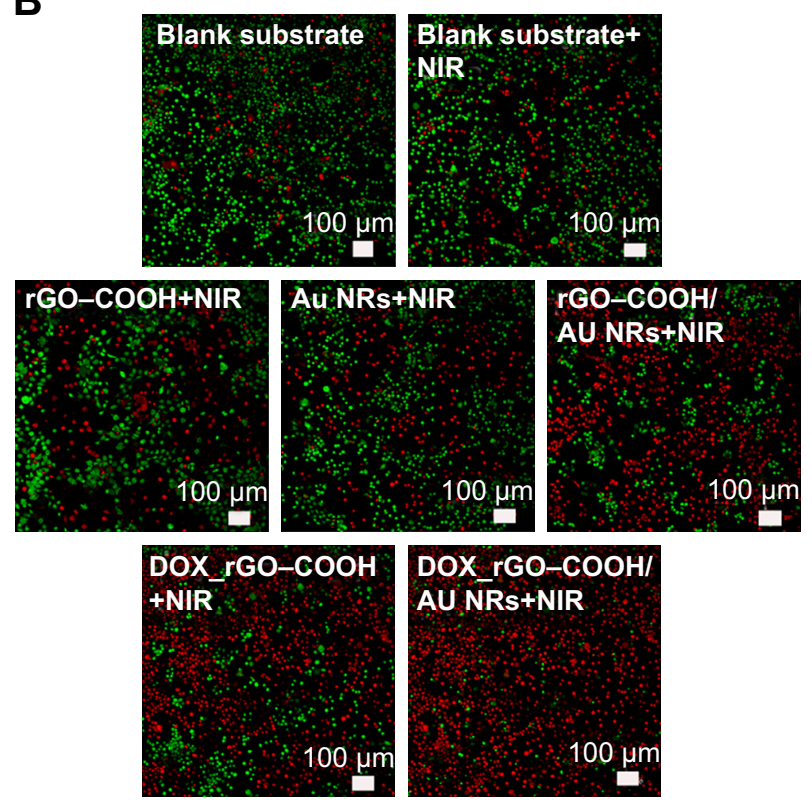

Figure 4 (A) Cell viabilities of A-43I cells in different groups with or without NIR radiation assessed by CCK-8 assay. The groups included (I) TCPS, (2) blank glass slide, (3) rGO-COOH, (4) Au NRs, (5) rGO-COOH/Au NRs, (6) DOX_rGO-COOH, and (7) DOX_rGO-COOH/Au NRs. (B) Confocal images of A-43I cells cultured in different groups stained by $\mathrm{Ca}-\mathrm{AM}$ and PI after NIR radiation. The live and dead cells were stained simultaneously with green and red fluorescence, respectively. The scale bars are all $100 \mu \mathrm{m}$. Top: blank glass slide, blank glass slide + NIR; middle: rGO-COOH + NIR, Au NRs + NIR, rGO-COOH/Au NRs + NIR; bottom: DOX_rGO-COOH + NIR, DOX_rGO-COOH/Au NRs + NIR.

Abbreviations: Au NRs, gold nanorods; DOX, doxorubicin; rGO-COOH, carboxylated-reduced graphene oxide; NIR, near infrared. 
to confirm live (green) and dead (red) cells, respectively. The results were consistent with the above quantitative assessment. In the confocal microscopy images (Figure 4B), cells in the control group display highly intense green fluorescence before and after NIR radiation, suggesting that the light does not damage the cells. Some cells incubated with $\mathrm{rGO}$ $\mathrm{COOH}$ or $\mathrm{Au}$ NRs are dead under NIR radiation showing red fluorescence. This proves that $\mathrm{rGO}-\mathrm{COOH}$ or $\mathrm{Au}$ NRs is cytotoxic by absorbing and converting the light to heat. Meanwhile, cytotoxicity is much higher for $\mathrm{rGO}-\mathrm{COOH} / \mathrm{Au}$ NRs under the same conditions. This can be attributed to the coupling of the SPR of Au NRs with the laser reduction of rGO-COOH. ${ }^{33}$ According to previous reports, ${ }^{33,57}$ we think that $\mathrm{Au}$ nanostructure can serve as photothermal sources through nonradiative decay and also act as local nanoantenna to enhance the optical energy absorption of graphene at a selected plasmon frequency. The most significant cell death is observed in the system with DOX_rGO-COOH/Au NRs with negligible green fluorescence. Taken together, the synergistic effects of PTT and CT are responsible for the improved therapeutic efficacy of the film.

\section{In vivo evaluation of (DOX_rGO- $\mathrm{COOH} / \mathrm{Au} \mathrm{NRs})_{4}$ multilayer}

This study aimed to demonstrate the application of the film for treating superficial tumors on the skin. With

A

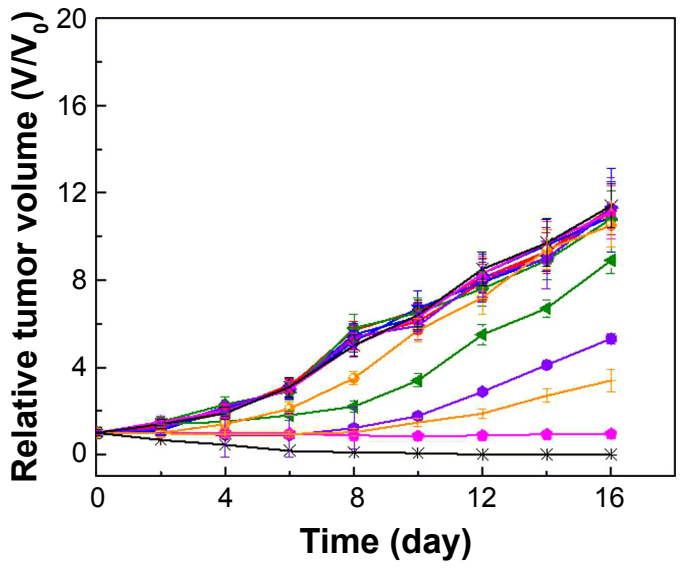

the positive in vitro results, we investigated the in vivo chemo-photothermal therapeutic effect in mice bearing human subcutaneous tumor cells, A-431. The as-developed DOX_rGO-COOH/Au NRs plaster was pasted onto the skin surface of the tumor sites at the beginning of the animal experiments. This treatment was nonsurgical and noninvasive.

The tumor-bearing mice were divided into seven groups, namely those with blank nonwoven substrate, $\mathrm{rGO}-\mathrm{COOH}$, $\mathrm{Au}$ NRs, rGO-COOH/Au NRs, DOX_rGO-COOH, DOX_ $\mathrm{rGO}-\mathrm{COOH} / \mathrm{Au} \mathrm{NRs}$, and that without any treatment. Half of the mice in each group was subjected to NIR laser $(808 \mathrm{~nm}$, $0.7 \mathrm{~W} \cdot \mathrm{cm}^{-2}$ ) for 10 minutes, and the remaining left half without radiation exposure were used as controls.

The antitumor therapeutic effect can be analyzed quantitatively by monitoring the change in tumor volume over time after treatment, and the tumor growth profiles are shown in Figure 5A. The growth rates of the seven groups are compared and a significant difference is noted. Tumors in the mice of the control groups exhibit continuous and rapid growth, even after NIR radiation, which indicates that the NIR laser does not have any damage to the tumors. In contrast, in the case of DOX_rGO-COOH-treated group, although initially there is slight inhibition of tumor growth without laser radiation due to the toxicity of DOX, the tumor finally grows to the same level as that in the group without any treatment; however, the tumor growth is suppressed a lot

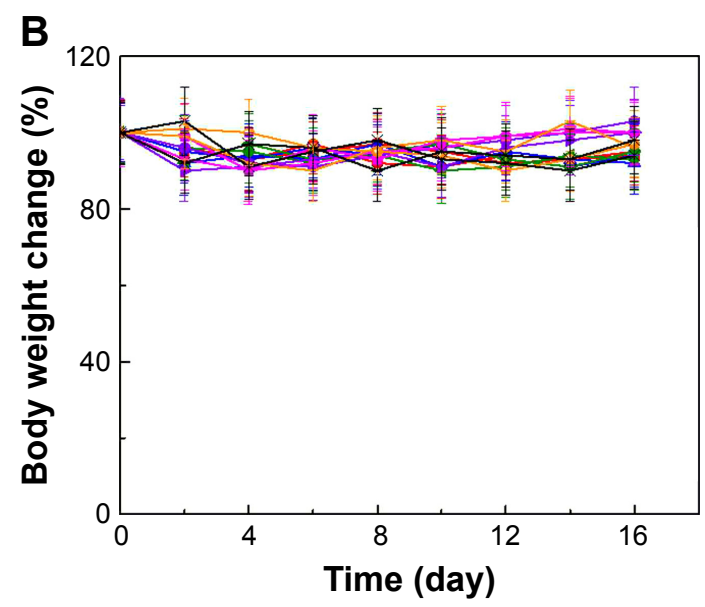

\begin{tabular}{ll|}
$\rightarrow-$ Control & $\star$ rGO-COOH/Au NRs \\
$\rightarrow-$ Control + laser & - rGO-COOH/Au NRs + laser \\
$\rightarrow$ Blank & - DOX_rGO-COOH \\
$\rightarrow$ Blank + laser & $\rightarrow$ DOX_rGO-COOH + laser \\
$\rightarrow$ rGO-COOH & $\rightarrow$ DOX_rGO-COOH/Au NRs \\
$\rightarrow$ rGO-COOH + laser & $\rightarrow$ DOX_rGO-COOH/Au NRs + laser \\
$\rightarrow$ Au NRs & \\
$\rightarrow$ Au NRs + laser &
\end{tabular}

Figure 5 (Continued) 


\section{C The mice treated with DOX_rGO-COOH/Au NRs under NIR irradiation}
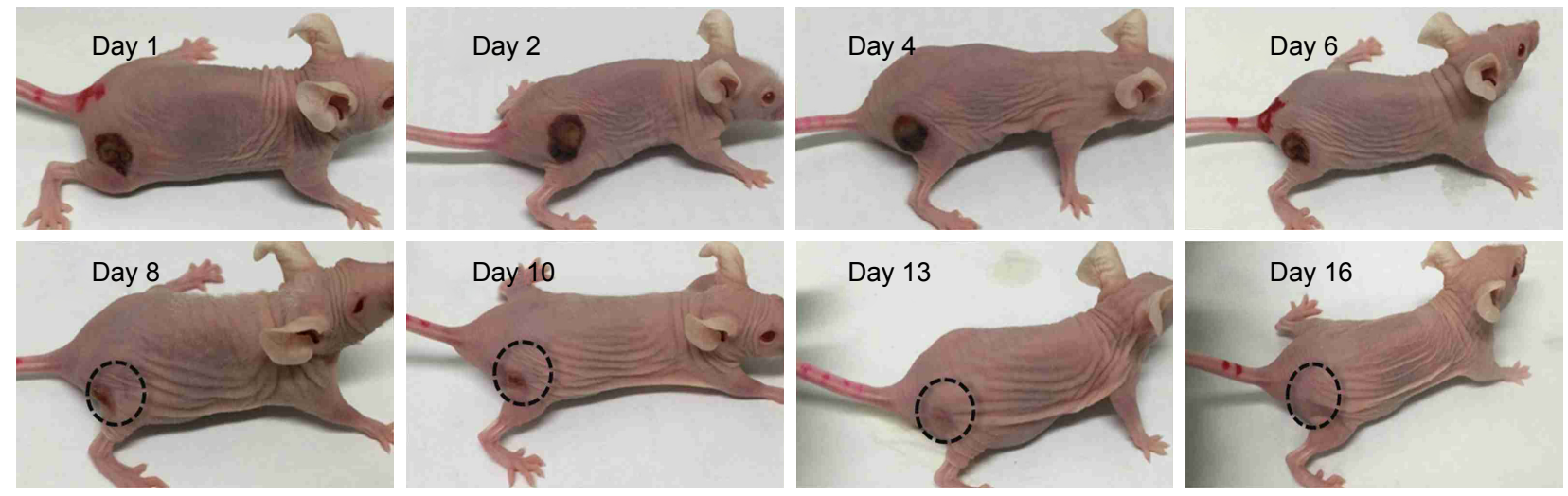

Figure 5 (A) The relative tumor size of mice in different treatment groups with or without NIR radiation. (B) The change in mouse body weight ratios in different treatment with or without NIR radiation. (C) Representative photographs of the mice at different times after treatment with DOX_rGO-COOH/Au NRs under NIR radiation. Abbreviations: Au NRs, gold nanorods; DOX, doxorubicin; rGO-COOH, carboxylated-reduced graphene oxide; NIR, near infrared.

after radiation in the same group. This suggests an enhanced toxicity of DOX due to its photo-activated release. In the case of Au NRs, the tumor grew rapidly without radiation, but with radiation, a strong tumor regression is observed. An almost similar tendency is noted for the $\mathrm{rGO}-\mathrm{COOH}$ treated mice. But, $\mathrm{rGO}-\mathrm{COOH} / \mathrm{Au}$ NRs shows a better antitumor effect than $\mathrm{rGO}-\mathrm{COOH}$ or Au NRs alone, such that the tumor does not grow further and was slightly suppressed. These data indicate that the combination of $\mathrm{rGO}-\mathrm{COOH}$ and $\mathrm{Au}$ NRs shows high efficiency in converting NIR laser to heat energy, which can kill the tumor cells. Notably, DOX_rGO-COOH/ Au NRs has the best antitumor effect among all the studied groups. For example, the tumor in the DOX_rGO-COOH/
$\mathrm{Au}$ NRs-treated mice under NIR radiation is eliminated completely without recurrence. Moreover, the DOX_rGO$\mathrm{COOH} / \mathrm{Au}$ NRs-treated mice were quite healthy without toxic effects and tumor recurrence over 60 days, while those in the other six groups showed an average life span of no more than 30 days. The body weight of the mice in all the groups was measured and the comparison is shown in Figure 5B. There were no significant changes in body weight of all mice indicating a negligible toxicity of all the systems in this study. Additionally, the images of the DOX_rGO-COOH/Au NRs-treated mice carrying tumors under NIR radiation were acquired during the treatment (Figure 5C). From the images, it can be observed that the treatment leads to the appearance
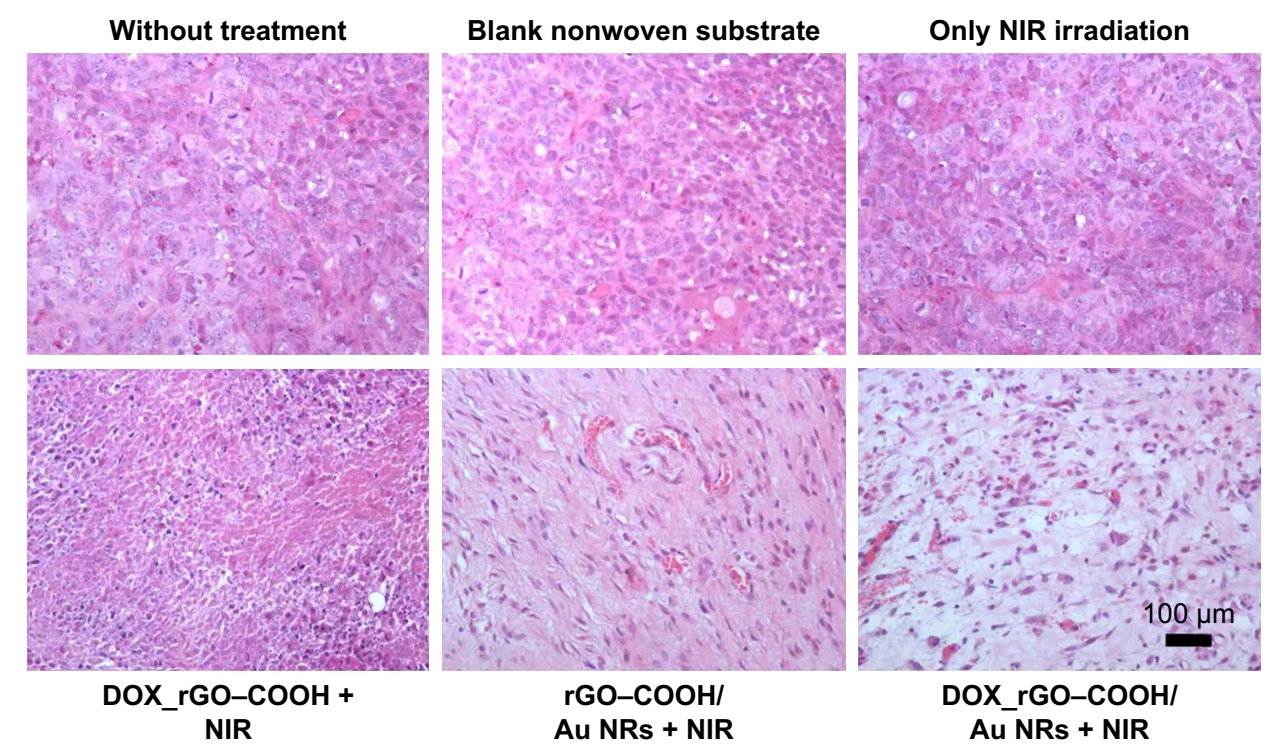

Figure 6 Images of H\&E-stained tumor sections collected from the mice bearing tumors after various treatments including DOX_rGO-COOH + NIR radiation, rGO$\mathrm{COOH} / \mathrm{Au}$ NRs + NIR radiation, and DOX_rGO-COOH/Au NRs + NIR radiation. The tumors were also collected from the two control groups and the group only receiving NIR radiation.

Abbreviations: Au NRs, gold nanorods; DOX, doxorubicin; rGO-COOH, carboxylated-reduced graphene oxide; NIR, near infrared. 
of superficial scabs at tumor sites and the scabs fall off at day 8 without recurrence in the following days.

Furthermore, the tumor sections were subjected to histological analysis. H\&E-stained tumor slices (Figure 6) reveal the presence of tumor lesions in the two control groups, and even under NIR radiation the lesions does not show any changes. In the case of the DOX_rGO-COOH-treated tumors receiving NIR radiation, the cells are destroyed partly. Obvious remissions of tumor cells can be observed only in $\mathrm{rGO}-\mathrm{COOH} / \mathrm{Au}$ NRs- or DOX_rGO-COOH/Au NRstreated mice with NIR radiation. Taken together, these results suggest that the chemo-thermal synergistic therapy of the DOX_rGO-COOH/Au NRs plaster is effective and might be applicable for treating superficial tumors.

\section{Conclusion}

In this study, we fabricated a composite nanomedicine system, DOX_rGO-COOH/Au NRs, with nonwoven fabrics as the substrate. The system was developed to be used as an anticancer plaster, especially, for treatment of superficial tumors. The plaster was demonstrated to be a powerful PT agent. It produced heat faster than that produced by $\mathrm{rGO}-\mathrm{COOH}$ or $\mathrm{Au}$ NRs alone when exposed to NIR radiation due to the synergistic effects between these two nanomaterials. Moreover, it also managed to enhance the release of encapsulated DOX when activated by NIR radiation. Accordingly, DOX_rGO$\mathrm{COOH} / \mathrm{Au}$ NRs showed high cytotoxicity and caused severe cell necrosis. Furthermore, the DOX_rGO-COOH/Au NRs plaster completely eradicated human squamous cell carcinoma in mice within 2 weeks without recurrence. Overall, the study suggests that the DOX_rGO-COOH/Au NRs plaster could be an effective, convenient, and noninvasive treatment option for treating superficial tumors.

\section{Acknowledgments}

This work was financially supported by the National Natural Science Foundation of China (Nos 21573126, 21675099) and the Natural Science Foundation of Shandong Province, China (No ZR2014BM025). W Qi thanks the Project of studying abroad for excellent young scholars sponsored by Qufu Normal University.

\section{Disclosure}

The authors report no conflicts of interest in this work.

\section{References}

1. Chen MC, Lin ZW, Ling MH. Near-infrared light-activatable microneedle system for treating superficial tumors by combination of chemotherapy and photothermal therapy. ACS Nano. 2016;10(1):93-101.
2. Abbas M, Zou Q, Li S, Yan X. Self-assembled peptide- and proteinbased nanomaterials for antitumor photodynamic and photothermal therapy. Adv Mater. 2017;29(12):1605021.

3. Robinson JT, Tabakman SM, Liang Y, et al. Ultrasmall reduced graphene oxide with high near-infrared absorbance for photothermal therapy. J Am Chem Soc. 2011;133(17):6825-6831.

4. Zou Q, Abbas M, Zhao L, Li S, Shen G, Yan X. Biological photothermal nanodots based on self-assembly of peptide-porphyrin conjugates for antitumor therapy. J Am Chem Soc. 2017;139(5):1921-1927.

5. Sherlock SP, Tabakman SM, Xie L, Dai H. Photothermally enhanced drug delivery by ultrasmall multifunctional $\mathrm{FeCo}$ /graphitic shell nanocrystals. ACS Nano. 2011;5(2):1505-1512.

6. Dong K, Liu Z, Li Z, Ren J, Qu X. Hydrophobic anticancer drug delivery by a $980 \mathrm{~nm}$ laser-driven photothermal vehicle for efficient synergistic therapy of cancer cells in vivo. Adv Mater. 2013;25(32):4452-4458.

7. Fu X, Wang X, Zhou S, Zhang Y. IONP-doped nanoparticles for highly effective NIR-controlled drug release and combination tumor therapy. Int J Nanomed. 2017;12:3751-3766.

8. Huang Y, Fan CQ, Dong H, Wang SM, Yang XC, Yang SM. Current applications and future prospects of nanomaterials in tumor therapy. Int J Nanomedicine. 2017;12:1815-1825.

9. Kemp JA, Shim MS, Heo CY, Kwon YJ. "Combo" nanomedicine: co-delivery of multi-modal therapeutics for efficient, targeted, and safe cancer therapy. Adv Drug Deliv Rev. 2016;98:3-18.

10. Luo D, Carter KA, Miranda D, Lovell JF. Chemophototherapy: an emerging treatment option for solid tumors. Adv Sci. 2017;4(1):1600106.

11. Yao X, Tian Z, Liu J, Zhu Y, Hanagata N. Mesoporous silica nanoparticles capped with graphene quantum dots for potential chemo-photothermal synergistic cancer therapy. Langmuir. 2017;33(2):591-599.

12. Pei P, Yang F, Liu J, et al. Composite-dissolving microneedle patches for chemotherapy and photothermal therapy in superficial tumor treatment. Biomater Sci. 2018;6(6):1414-1423.

13. Yao X, Niu X, Ma K, et al. Graphene quantum dots-capped magnetic mesoporous silica nanoparticles as a multifunctional platform for controlled drug delivery, magnetic hyperthermia, and photothermal therapy. Small. 2017;13(2):1602225.

14. Tian Z, Yao X, Ma K, et al. Metal-organic framework/graphene quantum dot nanoparticles used for synergistic chemo- and photothermal therapy. ACS Omega. 2017;2(3):1249-1258.

15. Li Y, Liu G, Ma J, et al. Chemotherapeutic drug-photothermal agent co-self-assembling nanoparticles for near-infrared fluorescence and photoacoustic dual-modal imaging-guided chemo-photothermal synergistic therapy. J Control Release. 2017;258:95-107.

16. Wang Y, Black KC, Luehmann H, et al. Comparison study of gold nanohexapods, nanorods, and nanocages for photothermal cancer treatment. ACS Nano. 2013;7(3):2068-2077.

17. Zheng X, Zhou F, Wu B, Chen WR, Xing D. Enhanced tumor treatment using biofunctional indocyanine green-containing nanostructure by intratumoral or intravenous injection. Mol Pharm. 2012;9(3):514-522.

18. Yu J, Javier D, Yaseen MA, et al. Self-assembly synthesis, tumor cell targeting, and photothermal capabilities of antibody-coated indocyanine green nanocapsules. J Am Chem Soc. 2010;132(6):1929-1938.

19. Li D, Huang J, Kaner RB. Polyaniline nanofibers: a unique polymer nanostructure for versatile applications. Acc Chem Res. 2009;42(1):135-145.

20. Hu M, Chen J, Li ZY, et al. Gold nanostructures: engineering their plasmonic properties for biomedical applications. Chem Soc Rev. 2006; 35(11):1084-1094.

21. Xuan M, Shao J, Dai L, Li J, He Q. Macrophage cell membrane camouflaged Au nanoshells for in vivo prolonged circulation life and enhanced cancer photothermal therapy. ACS Appl Mater Interfaces. 2016; 8(15):9610-9618.

22. Zhou M, Zhang R, Huang M, et al. A chelator-free multifunctional $[64 \mathrm{Cu}] \mathrm{CuS}$ nanoparticle platform for simultaneous micro-PET/CT imaging and photothermal ablation therapy. J Am Chem Soc. 2010; 132(43): 15351-15358.

23. Hessel CM, Pattani VP, Rasch M, et al. Copper selenide nanocrystals for photothermal therapy. Nano Lett. 2011;11(6):2560-2566. 
24. Huang X, Zhang W, Guan G, Song G, Zou R, Hu J. Design and functionalization of the NIR-responsive photothermal semiconductor nanomaterials for cancer theranostics. Acc Chem Res. 2017; 50(10):2529-2538.

25. Tian Q, Tang M, Sun Y, et al. Hydrophilic flower-like CuS superstructures as an efficient $980 \mathrm{~nm}$ laser-driven photothermal agent for ablation of cancer cells. Adv Mater. 2011;23(31):3542-3547.

26. Tian Q, Jiang F, Zou R, et al. Hydrophilic Cu9S5 nanocrystals: a photothermal agent with a $25.7 \%$ heat conversion efficiency for photothermal ablation of cancer cells in vivo. ACS Nano. 2011;5(12):9761-9771.

27. Moon HK, Lee SH, Choi HC. In vivo near-infrared mediated tumor destruction by photothermal effect of carbon nanotubes. ACS Nano. 2009;3(11):3707-3713.

28. Kim JW, Galanzha EI, Shashkov EV, Moon HM, Zharov VP. Golden carbon nanotubes as multimodal photoacoustic and photothermal highcontrast molecular agents. Nat Nanotechnol. 2009;4(10):688-694.

29. Li M, Yang X, Ren J, Qu K, Qu X. Using graphene oxide high nearinfrared absorbance for photothermal treatment of Alzheimer's disease. Adv Mater. 2012;24(13):1722-1728.

30. Yang K, Zhang S, Zhang G, Sun X, Lee ST, Liu Z. Graphene in mice: ultrahigh in vivo tumor uptake and efficient photothermal therapy. Nano Lett. 2010;10(9):3318-3323.

31. Shahil KM, Balandin AA. Graphene-multilayer graphene nanocomposites as highly efficient thermal interface materials. Nano Lett. 2012; 12(2):861-867.

32. Acik M, Lee G, Mattevi C, Chhowalla M, Cho K, Chabal YJ. Unusual infrared-absorption mechanism in thermally reduced graphene oxide. Nat Mater. 2010;9(10):840-845.

33. Turcheniuk K, Boukherroub R, Szunerits S. Gold-graphene nanocomposites for sensing and biomedical applications. JMater Chem B. 2015; 3(21):4301-4324.

34. Modugno G, Ménard-Moyon C, Prato M, Bianco A. Carbon nanomaterials combined with metal nanoparticles for theranostic applications. Br J Pharmacol. 2015;172(4):975-991.

35. Lin LS, Yang X, Niu G, Song J, Yang HH, Chen X. Dual-enhanced photothermal conversion properties of reduced graphene oxide-coated gold superparticles for light-triggered acoustic and thermal theranostics. Nanoscale. 2016;8(4):2116-2122.

36. Zedan AF, Moussa S, Terner J, Atkinson G, El-Shall MS. Ultrasmall gold nanoparticles anchored to graphene and enhanced photothermal effects by laser irradiation of gold nanostructures in graphene oxide solutions. ACS Nano. 2013;7(1):627-636.

37. Turcheniuk K, Dumych T, Bilyy R, et al. Plasmonic photothermal cancer therapy with gold nanorods/reduced graphene oxide core/shell nanocomposites. RSC Adv. 2016;6(2):1600-1610.

38. Shanmugam V, Selvakumar S, Yeh CS. Near-infrared light-responsive nanomaterials in cancer therapeutics. Chem Soc Rev. 2014;43(17): 6254-6287.

39. Ariga K, Hill JP, Ji Q. Layer-by-layer assembly as a versatile bottom-up nanofabrication technique for exploratory research and realistic application. Phys Chem Chem Phys. 2007;9(19):2319-2340.

40. Cui W, Li J, Decher G. Self-assembled smart nanocarriers for targeted drug delivery. Adv Mater. 2016;28(6):1302-1311.

41. Hillberg AL, Holmes CA, Tabrizian M. Effect of genipin cross-linking on the cellular adhesion properties of layer-by-layer assembled polyelectrolyte films. Biomaterials. 2009;30(27):4463-4470.

42. Blacklock J, Vetter A, Lankenau A, Oupický D, Möhwald H. Tuning the mechanical properties of bioreducible multilayer films for improved cell adhesion and transfection activity. Biomaterials. 2010; 31(27):7167-7174.
43. Tang Z, Wang Y, Podsiadlo P, Kotov NA. Biomedical applications of layer-by-layer assembly: from biomimetics to tissue engineering. Adv Mater. 2006;18(24):3203-3224.

44. Antunes JC, Pereira CL, Molinos M, et al. Layer-by-layer self-assembly of chitosan and poly $(\gamma$-glutamic acid) into polyelectrolyte complexes. Biomacromolecules. 2011;12(12):4183-4195.

45. Cui W, Wang A, Zhao J, Yang X, Cai P, Li J. Layer by layer assembly of albumin nanoparticles with selective recognition of tumor necrosis factor-related apoptosis-inducing ligand (TRAIL). J Colloid Interface Sci. 2016;465:11-17.

46. Zhan J, Wang L, Liu S, Chen J, Ren L, Wang Y. Antimicrobial hyaluronic acid/poly(amidoamine) dendrimer multilayer on poly(3-hydroxybutyrate-co-4-hydroxybutyrate) prepared by a layer-by-layer self-assembly method. ACS Appl Mater Interfaces. 2015;7(25):13876-13881.

47. Cheng M, Jiang C, Ding Z, Zhang Y, Fu Y, Shi F. Layer-by-layer self-assembly and disassembly of single charged inorganic small molecules: towards surface patterning. Phys Chem Chem Phys. 2013; 15(36):15172-15176.

48. Komiyama M, Yoshimoto K, Sisido M, Ariga K. Chemistry can make strict and fuzzy controls for bio-systems: DNA nanoarchitectonics and cell-macromolecular nanoarchitectonics. Bull Chem Soc Jpn. 2017; 90(9):967-1004.

49. Lee SW, Kim BS, Chen S, Shao-Horn Y, Hammond PT. Layer-by-layer assembly of all carbon nanotube ultrathin films for electrochemical applications. J Am Chem Soc. 2009;131(2):671-679.

50. Masuda K, Abe T, Benten H, Ohkita H, Ito S. Fabrication and conductive properties of multilayered ultrathin films designed by layer-bylayer assembly of water-soluble fullerenes. Langmuir. 2010;26(16): 13472-13478

51. Cai P, Feng X, Fei J, et al. Co-assembly of photosystem II/reduced graphene oxide multilayered biohybrid films for enhanced photocurrent. Nanoscale. 2015;7(25):10908-10911.

52. Yan J, Zhong T, Qi W, Wang H. The application of assembled inorganic and organic hybrid nanoarchitecture of Prussian blue/polymers/ graphene in glucose biosensing. J Inorg Organomet Polym Mater. 2015;25(2):275-281.

53. Ma J, Cai P, Qi W, Kong D, Wang H. The layer-by-layer assembly of polyelectrolyte functionalized graphene sheets: a potential tool for biosensing. Colloids Surf A Physicochem Eng Asp. 2013;426:6-11.

54. Qi W, Cai P, Yuan W, Wang H. Tunable swelling of polyelectrolyte multilayers in cell culture media for modulating NIH-3T3 cells adhesion. J Biomed Mater Res A. 2014;102(11):4071-4077.

55. Qi W, Xue Z, Yuan W, Wang H. Layer-by-layer assembled graphene oxide composite films for enhanced mechanical properties and fibroblast cell affinity. J Mater Chem B. 2014;2(3):325-331.

56. Nikoobakht B, El-Sayed MA. Preparation and growth mechanism of gold nanorods (NRs) using seed-mediated growth method. Chem Mater. 2003;15(10):1957-1962.

57. Hummers WS, Offeman RE. Preparation of graphitic oxide. J Am Chem Soc. 1958;80(6):1339.

58. Turcheniuk K, Hage C-H, Spadavecchia J, et al. Plasmonic photothermal destruction of uropathogenic $E$. coli with reduced graphene oxide and core/shell nanocomposites of gold nanorods/reduced graphene oxide. J Mater Chem B. 2015;3(3):375-386.

59. Yao YM, Liu QG, Yang W, Zhang M, Ma QY, Pan CE. Effect of spleen on immune function of rats with liver cancer complicated by liver cirrhosis. Hepatobiliary Pancreat Dis Int. 2003;2(2):242-246.

60. Lim DK, Barhoumi A, Wylie RG, Reznor G, Langer RS, Kohane DS. Enhanced photothermal effect of plasmonic nanoparticles coated with reduced graphene oxide. Nano Lett. 2013;13(9):4075-4079. 


\section{Supplementary materials}

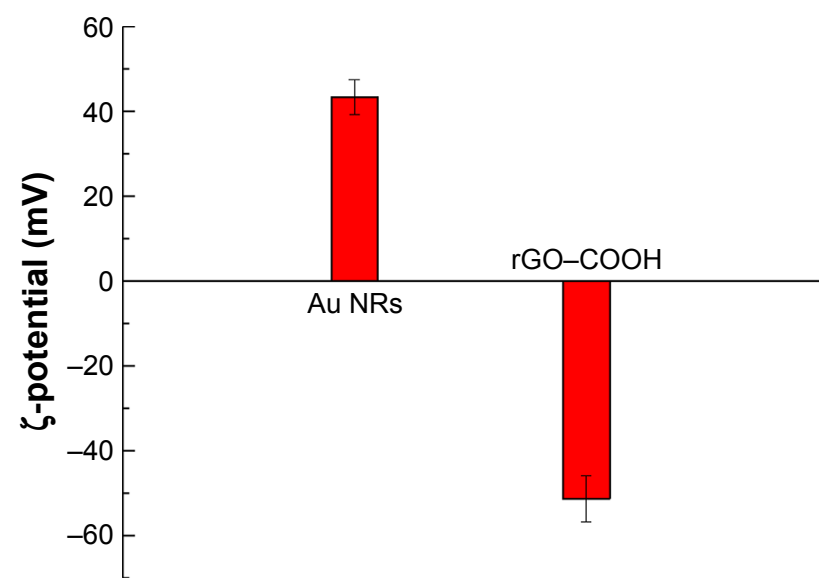

Figure SI Zeta-potential of Au NRs and rGO-COOH.

Abbreviations: Au NRs, gold nanorods; $\mathrm{rGO}-\mathrm{COOH}$, carboxylated-reduced graphene oxide.
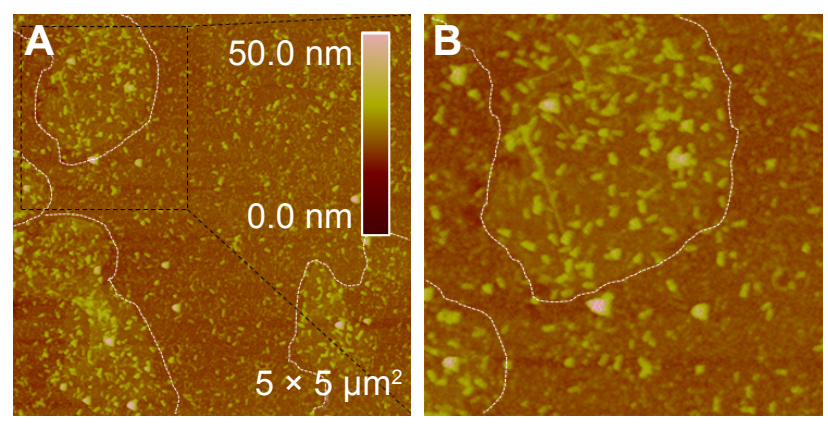

Figure S2 (A) AFM image of the surface of DOX_rGO-COOH/Au NRs multilayer. (B) The photo of DOX_rGO-COOH/Au NRs multilayer on nonwoven fabric. Abbreviations: AFM, atomic force microscopy; Au NRs, gold nanorods; DOX, doxorubicin; rGO-COOH, carboxylated-reduced graphene oxide.

International Journal of Nanomedicine

\section{Publish your work in this journal}

The International Journal of Nanomedicine is an international, peerreviewed journal focusing on the application of nanotechnology in diagnostics, therapeutics, and drug delivery systems throughou the biomedical field. This journal is indexed on PubMed Central, MedLine, CAS, SciSearch ${ }^{\circledR}$, Current Contents ${ }^{\circledR} /$ Clinical Medicine,
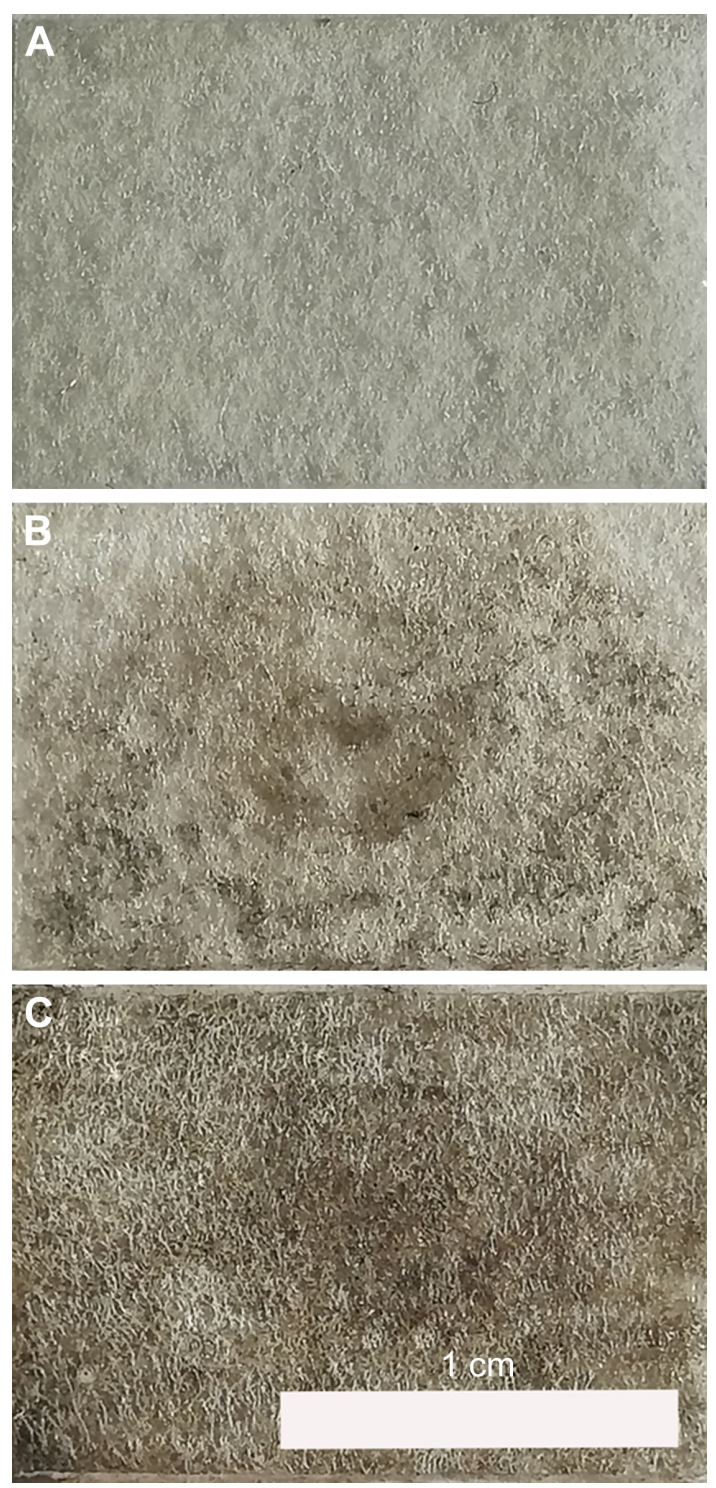

Figure S3 The photos of nonwoven fabric with DOX_rGO-COOH/Au NRs multilayer. (A) blank nonwoven fabric; (B) (DOX_rGO-COOH/Au NRs); (C) (DOX_rGO-COOH/Au NRs)

Abbreviations: Au NRs, gold nanorods; DOX, doxorubicin; rGO-COOH, carboxylated-reduced graphene oxide.

Submit your manuscript here: http://www.dovepress.com/international-journal-of-nanomedicine-journal 